\title{
Sports effects on ethical judgement skills of successful entrepreneurs: adaptation of interpretative phenomenological analysis
}

\author{
Nico van Rensburg \\ School of Business and Finance, University of the Western Cape, \\ Cape Town, South Africa, and \\ Ogujiuba Kanayo \\ School of Development Studies, University of Mpumalanga, Mbombela, \\ South Africa
}

Sports effects on ethical judgement
Received 19 August 2020 Revised 18 November 2020 28 February 2021 5 April 2021

Accepted 19 April 2021

\begin{abstract}
Purpose - This paper aims to identify how entrepreneurs' active involvement in sports/athletic training affects and adds to their overall ethical judgement skills within and outside the workplace.

Design/methodology/approach - This study adopted a qualitative approach and included a combination of 12 male and female entrepreneurs who were purposively selected based on the study's requirements. The primary data was collected through semi-structured one-on-one interviews, and interpretative phenomenological analysis served as the primary method of data analysis.
\end{abstract}

Findings - Findings from this study suggest that entrepreneurs' active involvement in sports/athletic training does indeed influence their ethical judgement skills all-round. Arising from a combination of sports involvement factors, a unique group of underlying elements surfaced that proves valuable accustomed relationships concerning the significant impact sports/athletic training have on successful entrepreneurs' ethical judgement skills.

Research limitations/implications - The active involvement in sports/athletic training undoubtedly plays a vital role in achieving entrepreneurs' daily ethical judgement ability. However, this study was limited to the opinion of a small sample of participants in a specific field. Also, this study's phenomenological nature requires the researcher's interpretation of the results to be viewed as the truth.

Practical implications - This study provides a new perspective and validates how purposeful involvement in sports/athletic training regimens can boost the ethical judgement skills of entrepreneurs allround. This study also proves powerful and new insight into the unique relationships among the accustomed factors and the underlying elements thereto - contributing beyond existing theory.

Originality/value - This study is novel and provides new and powerful insight into the ethical judgement skills and benefits derived thereof that can be developed by entrepreneurs from the active involvement in sports/athletic training.

Keywords Performance, Entrepreneurship, Ethics, Sport, Success, Athletic training

Paper type Research paper

\section{Introduction}

Over the years, ethics and its role in effective business decision-making practices have been an area of great debate (Hays, 2003). Similarly, the concept of entrepreneurial success and its close connection with ethical judgement ability and the role it is believed to play in obtaining positive results has also drawn considerable attention (Calvo, 2011; Mukerjee, 2016; 
Razmus and Laguna, 2018). Ancient greats such as Marcus Aurelius, Seneca, Plato, Epictetus and Aristotle all laid significant claims on the value of establishing proper ethics all-round (Holiday, 2015). Today, entrepreneurs and business leaders alike all face various challenges regarding the execution of proper ethics and judgement while under extreme pressure. Considering the on-going fluctuation in the current global economy, it certainly does not make things any easier for those looking to top the ladder of success in their respective fields. Temptations are high, and as with everything in life, there is always a price to pay. A recent corporate fraud survey indicates that South Africa's economic crimes remain at a record high with no real indication of lessening in the years to come (PWC, 2020). Holiday (2015) explains that implementing sound ethical judgement carries tremendous weight when it comes to forging a trustworthy and lasting entrepreneurial reputation. Vitel et al. (2010) elaborate and state that a single misguided approach or decision can ruin years of hard work and ultimately halt an entire entrepreneurial endeavour. Thus, aspects surrounding the ethical judgement skills of entrepreneurs, specifically, remain an area that requires further and more rigid attention. Pritchard and Burton (2014), Noval (2016) and Vriend et al. (2016) all touched base on a combination of extra-curricular activities, ethical codes of conduct, accustomed personal behaviours and personal development and leadership training that is believed to contribute to overall ethics in entrepreneurship. However, entrepreneurs' consistent involvement in sports/athletic training as an extracurricular activity and how it is believed to cognitively forge and contribute to the establishment of improved ethical judgement skills remains relatively unexplored (Thorne and Saunders, 2002; Waegeneer et al., 2017).

In the past, Ilies et al. (2005) investigated a combination of self-aspects, which are believed to highly influence ethical judgement in terms of individual thoughts, feelings, actions and behaviours. Lopez et al. (2005) and McCabe et al. (2006) adds to the findings of Ilies et al. (2005) and identified aspects such as demographics, education, social involvement, physical upbringing and cognitive ability as additional influential factors contributing to ethical judgement among individuals. Other researchers such as Friedman (2014) and Van Rensburg and Kanayo (2020) found that besides the physical benefits that can be obtained from regular exercise, the mental benefits derived are truly immeasurable. It is, therefore, evident that a unique combination exists between sports involvement/athletic training that stimulates the mind of an individual to value the process of improving the self consistently and ethically. This type of approach is believed to highly contribute to policy areas such as enhancing entrepreneurial conduct and promoting ethicality within educational curricula, politics and society consistently. It is absolutely critical to continually explore the accustomed approaches taken by rising South African entrepreneurs who are considered ethically sound within their business approach. This will not only assist in finding the ultimate pathway on how to overcome unethical temptations but also bridge the gap and create a platform for others to build on. For the purpose of this study, the researcher chose to take a narrowed approach towards the effects of physical training in sports and the essential factors derived from performance-based training that positively affects entrepreneurs' ethical judgement skills on a day-to-day basis. Elements such as fitness, strength and conditioning and endurance training in sport, along with the deriving factors thereof, such as attitude, motivation and commitment, will thus be the main areas of focus.

\section{Literature review}

\section{Sports involvement and athletic training}

Over the years, the active involvement in sports/athletic training has been identified by many researchers, sport and business enthusiasts as an activity that delivers a variety of 
benefits (Bredemeier and Shields, 2006; Weiss and Gill, 2005). Critical aspects such as physical, emotional and cognitive development derived from sports involvement/athletic training prove to be invaluable (Bredemeier and Shields, 2006; Weiss and Gill, 2005). Rechner and Smart (2012) posit that depending on the type of exposure, positive or negative, it largely contributes to an individual's choice of ethical behaviour learned through a particular type of sport or athletic training activity. Rechner and Smart (2012) also state that the duration of an individual's athletic or business career largely depends on his or her choice of ethical behaviour. It is, therefore, evident that individuals who frequently participate in sports/athletic training will consist of a more diversified approach towards certain events or circumstances, whether sport or business-related (Rechner and Smart, 2012). Aspects such as integrity, respect, confidence and humility derived from sportsmanship can, therefore, impact an individual's ethical decision-making ability significantly (Agnew et al., 2017). It is, therefore, safe to say that an entrepreneur's active involvement in sports/athletic training builds character; however, the type of character strongly depends on the motive behind the particular individual's first-hand choice of involvement (Chandler and Goldberg, 1990; Holiday, 2016). Thus, it is evident that sports involvement/athletic training surfaces as a unique mechanism through which participating individuals, in this case, entrepreneurs, continuously learn from events that eventually shapes who they are or become away from sports (Rechner and Smart, 2012).

\section{Ethical aspects involving sports and athletic training}

Morris (2006) and Holiday (2016) state that the search for recognition and the need to be validated by others triggers various individuals to partake in sports/athletic training for the wrong reasons. This type of behaviour often leads to a lack of social and environmental responsibility, as egotism overtakes humility by expressing carelessness and self-upheaval (Holiday, 2016; Morris, 2006). This sadly often leads to the end of various, once-glamorous looking careers in both the sport and business arenas (Rechner and Smart, 2012). Aspects such as greed, arrogance, evil, stupidity and personality disorder lead to many high-profile achievers losing it all in a short period of time. However, Morris (2006) and Holiday (2016) states that, on the other hand, the majority of successful individuals have come to realise these associated pitfalls. Therefore, thriving individuals are attempting to focus on the positives and use the benefits derived from sports involvement/athletic training to their absolute advantage. This summarises the fact that sound ethical judgement ability highly depends on the type of environment athletes, entrepreneurs and corporate leaders get introduced to and find themselves familiar with (Belle and Cantarelli, 2017; Rechner and Smart, 2012; Rees et al., 2019). Thus, when it comes to managing and leading people or teams effectively, along with building and solidifying relationships all-round, professionals functioning in environments where good sportsmanship, honesty and integrity dominates, are often more ethical and open to others through expressing true morale, discipline, integrity, humility and gratification no matter the situation (Rechner and Smart, 2012).

\section{Performance factors and ethical judgement in entrepreneurship}

Chang et al. (2017) and Florin-Valentin and Dariusz (2019) states that accustomed performance factors such as developing a positive attitude, motivation and commitment can indeed derive from consistent and performance-based training (Chang et al., 2017; FlorinValentin and Dariusz, 2019). Florin-Valentin and Dariusz (2019) continue and posits that active and constant involvement in some type of athletic or sports training give individuals more energy, endurance and open-mindedness when it comes to their overall judgement ability. It also develops within participating individuals a better and more understanding 
character that favours others' needs and handles situations more ethically around them (Chang et al., 2017). This proves that the challenge that often comes with physical training in preparation for a specific event enlightens a type of spirit that longs to get better, focussed on making the best of life's challenges and opportunities at the specific time (Chang et al., 2017; Florin-Valentin and Dariusz, 2019). This correlates nicely with Bandura's self-efficacy theory applied in this study, as it narrowly relates to the positive effects of motivation on human behaviour (Bandura, 1993). It is, therefore, evident that the positive outcome of the benefits derived from sports involvement/athletic training will enhance both personal conduct and promote ethicality within various systems across a combination of sectors and industries, specifically in entrepreneurship. The ability to train hard and express the benefits derived from hard work when participating in sports/athletic training; therefore, if approached correctly, will, undoubtedly, lead to improved ethical judgement, which in return ensures consistent and positive performance all-round (Fischer, 2015; Germain, 2010).

\section{Ethical judgement in entrepreneurship in South Africa}

Entrepreneurship activity in South Africa is undoubtedly on the rise in various sectors (Chimucheka, 2020). The enhancement of general entrepreneurial conduct, therefore, remains of utmost importance. Considering the high rates of unemployment and the vast array of unethical events and crime-related activities currently taking place across the country, often tempts numerous entrepreneurs to engage in the quickest way out to generate and maximise profits (Friebel et al., 2013; Statistics South Africa, 2019). The fact that this does not always entail the right way out, which often takes much longer and requires a bit more patience and integrity, proves to be an area that requires specific attention. With the ethical benefits that can be derived from the active involvement in sports/athletic training, entrepreneurs must put their focus on developing a solidified intellectual system that entails a foundation that is built on trust and good ethics all-round (Morris, 2006; Holiday, 2016). When looking at the agricultural sector in South Africa specifically, it remains under severe pressure (Cotterill, 2020). Cotterill (2020), states that numerous elements play a role in the day-to-day successes and failures of agricultural operations. Thus, it requires entrepreneurs to adapt more frequently and to develop systems that encourage ethical judgement in often some of the most daunting scenarios (Morris, 2006; Holiday, 2016). It is, therefore, evident that regardless of the situation or circumstance, ethical conduct and judgement ability should be critically addressed, analysed and professionally integrated within existing personal and entrepreneurial structures continuously.

\section{Theoretical overview}

Lederman and Lederman (2015) state that it is critically important for a researcher to apply a theoretical basis to a study. In this study, the researcher adopted the view that entrepreneurs who actively participate in sports/athletic training develop unique factors that enhance their overall ethical judgement skills. Aspects such as attitude, motivation and commitment, therefore, serve as critical elements that both psychologically and physically strengthen entrepreneurs all-round. For the purpose of this study, the researcher applied the theory of self-efficacy as a theoretical foundation. Bandura (1993) explains the theory of self-efficacy to be in close connection with humans' personal experience, behaviour, psychological and motivational processes that encourage both specific and ultimate performance; thus, perfectly aligning with the strategic approach of this study. Below, follows a structured outline providing a brief overview of Bandura's beliefs: 
Motivational processes. Bandura (1993) states that a person's actions are believed to involve a variety of genetic, responsive, shared and intellectual relationships that forges motivation. This explains that motivation generated through applied attitude and effort establishes a high level of commitment and ethical responsibility that significantly impacts mind, body and spirit (Bandura, 1993).

Cognitive processes. Bandura (1993) states that every individual consists of some sort of cognitive ability to mentally create a particular feeling or circumstance longed for. If channelled correctly, a person's cognitive ability serves as a psychological weapon that allows for creating immense self-confidence, strategy, ethicality and personal drive over a period of time (Bandura, 1993).

Affective processes. Bandura (1993) states that an individual's level of faith in himself or herself will highly determine how effective the particular person will handle times of distress. Thus, if channelled correctly, an individual's level of self-belief will allow him or her to act more rightfully and execute a desire that maintains a more ethical approach to life (Bandura, 1993).

Selection processes. Bandura (1993) states that an individual often becomes a reflection of the environment he or she spends most of their time in. It is, therefore, critical for an individual to continually evaluate his or her surroundings and consistently initiate adequate changes that encourage consistent growth, positivity and ethicality all-round (Bandura, 1993).

Theoretical guideline. The belief of Bandura (1993) that motivational, cognitive, affective and selection processes form bondage with an entrepreneur's level of self-belief, can eventually determine how it is strategically applied. An entrepreneur's psychological approach and how he or she chooses to manoeuvre certain situations, therefore, eventually gives rise to determining their occupational fate. As a result, it remains critical to get behind the true factors and forces that are believed to contribute to entrepreneurs' ethical judgement ability all-round. Below, follows a representation of the critical factors addressed (Tables 1 and 2):

\section{Sport involvement factors addressed \\ Deriving factors.}

Conceptual model. Below, follows a graphic image addressing the three overreaching sport involvement factors along with the three deriving performance factors, neatly indicating how each factor is believed to be interconnected with one another, positively impacting entrepreneurs' overall ethical judgement ability (Figure 1).

As derived from the graphic image above, it is clear that for entrepreneurs to execute sound ethical judgement consistently, the consistent flow and execution of an advanced level of sports involvement/athletic training regimes and factors are required.

Fitness training

Strength and conditioning training

Endurance training
Fitness training involves all activities that can lead to improved physical and cognitive functioning, improving one's ability to confidently participate in leisure that significantly contributes to enhance social experience (Paoli and Bianco, 2015)

Strength and conditioning training involves the entire physical development of an individual that is required to allow him or her achieve maximum performance (Jarvis, 2015)

Endurance training can be defined as the act and ability to exercise frequently, to increase one's personal level of endurance to maximum capacity (Runacres et al., 2019)
Sports effects on ethical judgement

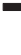




\section{Methods}

For the purpose of this study, Interpretative Phenomenological Analysis (IPA) was applied as the main methodological foundation. Pietkiewicz and Smith (2012) state that the goal of phenomenological research is to try and classify the critical mechanisms of certain practices or occurrences, which distinguishes certain individuals from others in terms of uniqueness. Smith et al. (2009) contribute and states that the primary purpose of IPA research, however, is to get as close as possible to the research participant, as to make clear meaning of the particular participant's exact life experiences. Therefore, IPA as method allows for greater flexibility and responsiveness, which encourages a continuous flow of questioning, interpretation and critical sense-making of the meaning of the phenomena under investigation, for both the participant and the researcher (Smith et al., 2009; Willig, 2001). Thus, by attempting to make meaning of how selected participants view and apply certain sports involvement/athletic training factors, and how it positively affects their ethical judgement skills as a whole, makes the implementation of IPA as the primary method of data analysis most relevant.

\section{Characteristics of participants}

Population. In this study, the key participants included were 12 successful male and female entrepreneurs who currently operate within the Western Cape's agricultural sector in South Africa. Smith et al. (2009) consider the inclusion of 12 participants within an IPA study as more than appropriate. To add diversification to the group of participants, the researcher chose to include participants from both white and black ethnic groups. Because of the complexity, current ethical challenges and varying elements involved in the agricultural sector, the inclusion of entrepreneurs operating in this sector is deemed most appropriate for the purpose of this study.

Sampling. For the purpose of this study, purposive and snowball sampling were applied to select the key participants. The study's unique nature and close connectedness with each of the participants' true lived experiences, calls for applying both sampling methods to

Table 2.

Types of accustomed personal performance and ethical judgement skills
Attitude

Motivation

Commitment
Attitude can be defined as a response, either physical or mental, towards someone or something, expressing a feeling or act, positive or negative (Hodges and Logan, 2012) Motivation can be classified as a combination or set of psychological processes, directed towards establishing significant intensity and persistence of personal behaviour (Wang et al., 2018)

Commitment refers to the promissory decision to make or do something wholeheartedly in the expectance of retrieving a positive result (Trompetter et al., 2017)

\section{Figure 1.}

Combination and relationship between sport involvement/ athletic training and the deriving factors contributing to entrepreneurs' ethical judgement ability

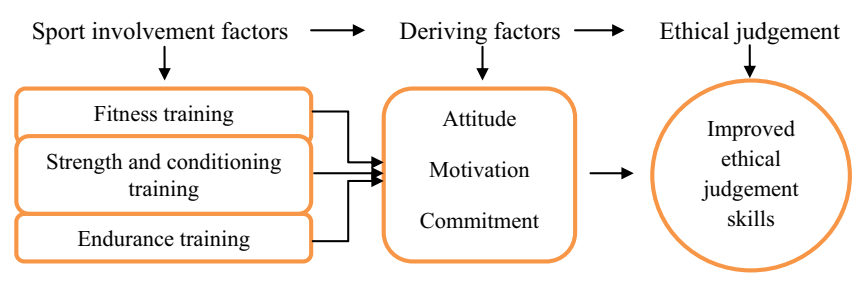


establish a platform for the researcher to obtain, refine and process only the most delicate information that fits the scope of this study (Smith et al., 2009).

\section{Purposive sampling}

Selection. Etikan et al. (2015, p. 2) define purposive sampling as "the deliberate choice of a participant owing to the qualities the participant possesses". Thus, the first three participants were purposively selected according to their current level of involvement in sports-related activities and how these activities positively impact their overall ethical judgement skills as entrepreneurs.

Success criteria. Participants who generated turnover exceeding ZAR6,000,000 annually and conducting uninterrupted business for more than 10 years were classified as successful, and vice versa. Each of the first three participants matched this criterion. For this, the researcher considered both organisational effectiveness and efficiency measures (Lekovic and Maric, 2015). The researcher also obtained expert guidance and statistical data from Agri SA and the Elsenburg Agricultural Institute in the Western Cape, South Africa, which provided further direction in selecting the desired participants that match the study's criteria.

\section{Snowball sampling}

Selection. Naderifar et al. (2017, p. 2) define snowball sampling as the use of "existing study subjects to recruit future subjects among their acquaintances". Each of the 3 selected participants advised the researcher on at least 3 other possible participants who, to their knowledge, also met the study's selection criteria, rounding out the total of 12 participants.

Screening. To ensure the validity of the accompanying nine participants, the researcher successfully screened and matched the demographics, success criteria and years in business, and current industry sector operational activity of these participants with the statistical data obtained from Agri SA and the Elsenburg Agricultural Institute. To the researcher's advantage, each of the nine accompanying participants perfectly matched the study's selection criteria. Each of the nine accompanying participants' interest and involvement in sports/athletic training was also confirmed.

Confirmatory details of participants. In terms of maturity levels, participant ages ranged from 29 to 51 years. Of the 12 participants, 6 were soft-fruit farmers, 3 were stone-fruit farmers, with the remaining 3 being vegetable farmers, respectively. In terms of ethnicity, five participants were white males, two were white females, whereas the remaining were three black male individuals and two black female individuals. To the researcher's advantage, each participant also conducted business for longer than 10 years continuously. A more detailed account of the participants' characteristics appears in Table 3.

Instruments. Apart from the overreaching research question guiding the research output: "How does the involvement in sports/athletic training affect the ethical judgement skills of successful entrepreneurs in South Africa?" this study used a one-on-one interview guideline. Sandelowski (2002), states that one-on-one interviews allow the researcher the opportunity to closely interact with participants on a personal level to probe and explore hidden meanings and understanding with greater intent. Thus, a professionally constructed interview schedule served as the basis for the data collection procedure, which contained a variety of semi-structured and open-ended questions concerning the phenomena under investigation. A sample of the questions that were included in the questionnaire is presented in the procedure section below. To ensure content validity and proper structure, the researcher insisted that the guideline be cross-checked by two experts in the field. 


\begin{tabular}{lccllcll}
\cline { 2 - 7 } JEEE & Participant & Age (yrs) & Gender & Ethnicity & In business (yrs) & Annual turnover & Industry sector \\
\cline { 2 - 7 } & 01 & 29 & Male & Black & 10 & ZAR6,000,000+ & Stone fruit \\
& 02 & 51 & Male & White & 25 & ZAR6,000,000+ & Soft fruit \\
& 03 & 32 & Female & Black & 11 & ZAR6,000,000 + & Stone fruit \\
& 04 & 47 & Male & White & 20 & ZAR6,000,000 + & Vegetable \\
& 05 & 36 & Male & White & 15 & ZAR6,000,000+ & Soft fruit \\
& 06 & 42 & Male & White & 12 & ZAR6,000,000+ & Soft fruit \\
& 07 & 39 & Female & Black & 14 & ZAR6,000,000 + & Stone fruit \\
Table 3. & 08 & 41 & Female & White & 12 & ZAR6,000,000 + & Soft fruit \\
Overview of & 09 & 30 & Male & Black & 10 & ZAR6,000,000 + & Vegetable \\
participants' & 10 & 38 & Male & White & 13 & ZAR6,000,000 + & Soft fruit \\
characteristics & 11 & 44 & Male & Black & 15 & ZAR6,000,000 + & Vegetable \\
\hline
\end{tabular}

\section{Procedure}

Ethical clearance and informed consent. After receiving the Research Ethics Committee's approval, the researcher was able to proceed with the sampling process to select the 12 participants. The interviews were conducted over a period of three months, from March 2020 to May 2020. To ensure proper consent, the researcher supplied each participant with a consent form and study information sheet electronically to clarify the reason for their selection/inclusion in the study. The consent form also explained the protection of their identities and informing them that they were free to withdraw their consent at any stage from the study if they wished to do so. To the researcher's advantage, a consent approval from each participant was received, and a convenient time and interview location were then arranged.

Research questions. In the interview, the researcher asked each participant to respond to the following sample questions: "What does personal fitness mean to you?" "Do you feel being fit is advantageous?" Why or Why not?" "What's your viewpoint on the physical and psychological impact of strength and conditioning training on your personal self?" "Various people in business and sports feel that endurance training is as important as fitness and strength and conditioning training, do you agree?" "Why or Why not?" "How would you describe the impact that these training factors have on the development of your personal attitude, motivation, and commitment levels?" "Please explain". "Do you agree that fitness training, endurance, and strength and conditioning training in association with the development of its deriving factors such as personal attitude, motivation, and commitment, impact your overall day-to-day ethical judgement ability as an entrepreneur?" "Please explain". Regarding the subject under investigation, each of the above research questions allowed the researcher to unlock the true lived experiences of each participant in great depth.

Interview schedule. Each of the above research questions allowed the participants to provide in-depth descriptions, perceptions and valuable add-on information of their personal lived experiences concerning the factors under investigation. All interviews were conducted in the utmost of private and convenient individual locations, ensuring maximum relaxation and limited to no interruptions at all times. Each interview lasted for about 45-60 min.

Data analysis. The data were analysed using IPA. According to Smith et al. (2009), the analysis of IPA data involves a systematic process. Smith et al. (2009) further state that the systematic process often gets divided into three separate phases to ensure the proper 
interpretation and accuracy of results. The researcher, therefore, strictly applied the following steps as outlined below:

Recording of data. During each interview, written notes and audio recordings were conducted to collect and store the data. The notes were analysed, and recordings were carefully listened to and transcribed verbatim. Each transcript was re-read multiple times to make precise meaning of each participant's exact lived experiences.

Formulation of themes. Only the most significant statements were extracted from the bulk of the information collected. The formulated meanings of the statements were then strategically categorised into clusters of themes. The findings were then strategically integrated into thorough narrative descriptions of each participant.

Validity of data. Bracketing and bridling techniques were applied to ensure proper interpretation of the results. In addition, credibility, transferability, dependability and confirmability measures were strategically applied to ensure that the data collected was correctly interpreted and truthful.

\section{Results and discussion}

\section{Results}

All participants thoroughly expressed and agreed to the fact that sports involvement/ athletic training indeed improves their ethical judgements skills considerably. Following each of the interviews and the data analysis phase, six major themes emerged, detailing the lived experiences, perspectives and beliefs on the phenomena under investigation. Each of the themes is categorised under two sub-sections below, with supporting excerpts from the interviews to illustrate the themes: fitness training, strength and conditioning, endurance training, attitude, motivation and commitment.

\section{Sport involvement factors}

Fitness training. Each of the participants consisted of a strong drive to engage in frequent fitness training. Some of them saw their actual fitness training as a sport in itself, whereas others viewed it as a substance required to merely excel at a specific or different type of interested sport. All of the participants highlighted several aspects that are believed to physically, psychologically and ethically contribute to their daily routines:

For me, fitness training is the antidote towards developing better self-confidence. I feel that the fitter I become, the more energetic and enthusiastic I am towards my day-to-day interactions with others. I also believe that psychologically, it has significantly contributed to me becoming more disciplined and ethical in my overall decision-making ability. Besides, being an entrepreneur, I can truly testify that working on my fitness really drives me to get better in all aspects of my life. It allows me to be more aware of my efforts, decisions and my surroundings. It forces me to continue improving, to ultimately become the best version of myself (Participant 11, 44 years of age).

Over the years, the discipline I have developed through consistent training definitely shaped the person I am today. I feel more motivated and confident in my overall approach to business and life and the challenge of wanting to stay fit drives me to keep growing as a person. To this day, fitness training teaches me to remain honest with myself and others - it is the only way to make true progress and to succeed moving forward. I can honestly say that fitness training gives me a competitive edge over my rivals. I have learned valuable lessons through fitness training, and still do, that contribute to me overpowering undesired circumstances in a way that I couldn't have done ever before (Participant 08, 41 years of age). 
Strength and conditioning. Each of the participants really had a strong appetite towards continually improving and maintaining a good level of physique. In addition, a strong mentality was both required and longed for by each of the participants. Apart from their engagement in focussed fitness training programs, whether in a public gym under supervision or at a private training facility at their homes, each of the participants expressed a strong urge to continue getting stronger and better themselves moving forward:

For me, training to get stronger grows not only my physique but also my mental strength. I always say to get fit is great, but to get strong and maintain the strength that you have built up over time, is what truly tests your inner spirit and character. The journey to get stronger each day is certainly a requirement; it makes me appreciate hard work and strengthens my overall commitment. The art of getting stronger both physically and psychologically breeds a strong sense of self-respect within me that contributes to me treating the interests of others with more respect (Participant 05, 36 years of age).

I genuinely believe strength and conditioning training adds to strengthening my overall faith - faith in myself, a higher power and belief that I can overcome any obstacle. To this day, I try to channel the discomfort I often experience with strength and conditioning training as a force that drives my overall personal development. This, in turn, allows me to be more approachable, which also makes me look different at certain and often challenging scenarios - there is no easy way out, it is the right way, or no way at all (Participant 04, 47 years of age).

Endurance training. Each of the participants had a longing for regular endurance training; in fact, this was a weekly goal. Apart from the frequent fitness and strength and conditioning training they engaged in on a daily basis, each of them shared a great passion for engaging in activities that regularly tested their fitness progress over a specific period. Whether cycling or running in the mountains, most of these endurance-training activities were completely self-driven, containing a handful of physical and psychological benefits allround:

For me, endurance training is the most difficult part; it tests my ability when no one is watching. I feel endurance training is crucial - with endurance comes pain, and with pain comes resilience, and from resilience comes personal drive and respect. If you want to remain competitive, endurance training is what keeps you ahead. I have also found that endurance training allows me to value the honest effort of others. It improves my overall judgement, which in turn leads to improved positive outcomes within and outside the workplace (Participant 10, 38 years of age).

Endurance training is critically important; I feel it keeps my mind and body in sync. Endurance training has taught me to keep going and keep on doing the right things repetitively. I also feel it challenges me to make a habit of setting an example to others; it surely does wonders to my being and decision-making ability. My motto: quitters never win, and winners never quit, is as true as it gets. I honestly believe that the benefits derived from endurance training help me to better and more ethically address complicated scenarios (Participant 02, 51 years of age).

\section{Ethical contribution of factors}

Attitude. Each of the participants expressed a tremendous attitude, not only enthusiastic but also positive and encouraging for those around them. Apart from general life and business experiences, it became evident that a large part of their attitudes got shaped through the constant involvement in sport and athletic training activities. The testing and forging of mental and physical skills through fitness, strength and conditioning, as well as endurance training consistently, undoubtedly, delivered astonishing results: 
To me, attitude is everything. Through time, I have learned that a positive attitude gives rise to a positive mind-set and without a positive mind-set, you will and cannot endure all the challenges life throws at you. My on-going effort in the gym has surely reaped great benefits. In essence, I value my health and appreciate the opportunities I get to keep improving myself now more than ever before. During each day that I train, I constantly remind myself to remain positive; it is the absolute key to obtaining lasting success. I can testify that consistent training with the right attitude attracts positive outcomes and favourable situations, which ultimately results in making improved and more ethical decisions all-round (Participant 12,50 years of age).

Working on my fitness, especially endurance training, has helped me develop a strong level of resilience all-round. I feel the constant challenge of pushing my body and mind to the limits has taught me to never give up and to focus more on doing the little things right. Life is certainly a process, and the process cannot be cheated - honesty and commitment eventually get rewarded. The establishment of a positive attitude is everything; it can build or destroy a good reputation in an instant. Over the years, fitness and training have taught me to program myself to always try and see the good in things. This seriously allows me to think more clearly and execute better judgement in some of the most testing circumstances (Participant 06, 42 years of age).

Motivation. Each of the participants had a powerful will to get better than what they were the day before, driven to expand both their personal and entrepreneurial horizons on a daily basis. Apart from a variety of experiences and setbacks faced in the past, it became evident that each of them consisted of a great level of excitement and inner drive, which they have developed over time. This motivated them to want to get better and to progress more consistently and ethically all-round:

Without a doubt, motivation is certainly the key to achieving consistent growth in life and business. I can honestly say that active involvement in sport severely strengthens my level of motivation to this day, and trust me, motivation breeds confidence. I purposefully try to channel my thoughts in such a way to motivate those around me as well; it establishes better support and trust between myself and those around me. I have also come to realise that my overall judgement in a variety of situations has changed - being motivated has taught me the value of expressing and maintaining proper ethics, no matter how challenging a situation, making the right call is absolutely critical (Participant 03, 32 years of age).

I have always been a great believer in doing the right thing. In today's world, you will get deceived if you are not sharp enough. Shortcuts in life, unfortunately, don't last. Through sports and training, I have come to realise what hard work entails - it completely transformed my character in such a way that it drives discipline and excellence continually. Making proper decisions in life and business is crucial. Sports and athletic training has developed in me the utmost motivation to do the right thing consistently - always placing the best interests of myself and others at the front of every important decision that I need to make (Participant 09, 30 years of age).

Commitment. Each of the participants expressed a significant level of commitment, not only to keep excelling in what they do but also to add value to the lives of the people around them. Apart from already carrying a heavy burden in terms of entrepreneurial responsibility, it became evident that each of the participants used the lessons and experiences learned from active involvement in sports/athletic training as stepping stones to improve and build on their level of personal commitment:

There are not many things in life that can stop a committed individual. For me, commitment to hard work is the absolute antidote towards achieving consistent results. My involvement in sports, and the training it takes to excel therein, has taught me valuable lessons on commitment. 
It allows me to keep at it when the majority has given up - the same counts when it comes to facing important decisions in my life and business. I can honestly say that the commitment to execute the right protocols and to conduct ethically sound judgement during pressurised events, has allowed me to navigate various pitfalls up to date. Thanks to sports and athletic training the benefits have certainly shaped my character for the better (Participant 07, 39 years of age).

To me, being committed indeed represents a variety of things. Throughout my career, I have noticed that one can become committed to either doing the right or the wrong thing and oftentimes unknowingly the wrong thing. Training has taught me the importance of quality repetition; through quality repetition, my thinking changed, which has taught me the powerful effect of remaining focussed on the right things. My overall decision-making ability has significantly improved, and I have come to understand the importance of committing wholeheartedly to the present moment. Each day, I face hundreds of choices; thus, the commitment I have established through strenuous training and exercise has taught me the value of always integrating proper ethics, both to myself as an entrepreneur and the outside world (Participant 10, 38 years of age).

Judgement/decision-making. Each of the participants expressed a significant level of positive attitude, motivation and commitment. Findings confirm that each of these factors contributes significantly to the personal approach and ethical judgement ability of each of the participants. Apart from applying what they have learned through fitness training, strength and conditioning and endurance training, their efforts and experiences generated are used to value and transform themselves into becoming more ethical in their overall approach:

My involvement in sports has undoubtedly contributed to my ethical reasoning ability in all facets of my life. There is something unique, almost special, which arises from pushing yourself to your physical limits. The discipline derived from consistent and enforced physical effort in training motivates me to make decisions strictly based on the moral impact thereof - both in business and my private life. I know the value of hard and focussed work; thus, I have the utmost respect for those who value the same. Sports/athletic involvement have and still do, contribute to me valuing the true impact of ethical decisionmaking ability. Whether in business or relationships, I have learned that the right decision today will establish a better tomorrow, and vice versa (Participant 10, 38 years of age).

To me, pushing myself to the limits in sports and training has certainly changed the way I look at life. I have concluded that finding an alternative way, such as sports and training to discipline your mind, body and spirit greatly affects how you approach and make your decisions in life. I can honestly say that physical training has impacted my overall ethical judgement ability tremendously. Besides, valuing my own effort and progress, I have come to learn to value the personal efforts and progress of those within and outside my circle as well. The execution of perfect honesty is crucial - thanks to sports and fitness training, I have been able to develop a greater sense of integrity towards my ethical approach and judgement ability all-round (Participant 01, 29 years of age).

\section{Discussion}

As presented across literature and derived from the results section above, findings confirm the uniqueness and extreme effectiveness of the combination of sport involvement factors and the factors derived from it that contribute to developing sound ethical judgement skills within entrepreneurs. For most of these participants, the deriving factors addressed, such as attitude, motivation and commitment began to take root from an early stage. However, as they became more mature and the pressures of life and entrepreneurial responsibility came into existence, they needed to combine their work/life balance with something external, 
which regularly challenged their inner being to progress. Although it appeared that all 12 participants had some prior knowledge and experience regarding the positive effects of sports involvement/athletic training, significant room for learning and improvement still existed. Thus, as presented in this study, all of the participants turned to sports involvement/ athletic training with a broader approach and much greater intensity. The appetite to improve themselves consistently, specifically their overall ethical judgement ability, was a force that needed to be owned. Participatory and sport involvement factors such as fitness training, strength and conditioning and endurance training, therefore, stretched each of these participants way beyond their personal limits, transforming them into becoming exceptionally trustworthy individuals. The results confirm that each participant took their active involvement in sports and athletic training as very serious, something they accounted for, giving them a defining competitive edge over their counterparts.

In their study, Rechner and Smart (2012) found that entrepreneurs who were actively involved in sports or who partake in specific sports training regimens to perform well at a desired level consisted of a tremendous character, attitude and high levels of motivation and commitment. Sports involvement/athletic training presented itself as a type of mechanism through which individuals constantly learn from events that eventually shape who they are or become away from sports (Rechner and Smart, 2012). Results from this study build on these findings, once again touching base on the powerful effects sports involvement/athletic training has on entrepreneurs' ethical judgement ability. When looking at the overall effect and impact these factors have had on entrepreneurs' ethical judgement ability, it directly associates with both participants' mental and physical abilities (Bredemeier and Shields, 2006; Weiss and Gill, 2005). This process correlates nicely with the theory of self-efficacy applied in this study, as Bandura (1993) believes there is a close connection between human motivation, psychology and physical performance. Thus, the constant involvement in sports/athletic training, creates a unique inner strength, an ability that drives entrepreneurs to become more diverse in their overall approach to life and business. Findings from this study show that each participant also became more socially and environmentally responsible over time. The positive effects derived from more focussed involvement in sports/athletic training transformed each participant internally to a significant extent. In their own unique way, each participant became more aware of the impact they have on their surroundings. This approach resulted in the participants becoming better leaders that value the importance of building and solidifying dedicated efforts and relationships through practicing improved ethical judgement all-round.

Chang et al. (2017) agree with this fact, as they found that the active and constant involvement in some type of athletic or sports training regimen gave participants more energy, endurance and developed within them a robust and trustworthy character. It is, therefore, evident that factors affecting the ethical judgement skills of entrepreneurs appear to be more dominant within purposefully driven individuals. The importance of attempting to forge a type of spirit that longs to get better, helps entrepreneurs make the best and most ethical decisions regarding life's challenges and opportunities (Chang et al., 2017; FlorinValentin and Dariusz, 2019). The underlying elements acting as drivers towards generating a positive attitude, motivation and commitment activated through sports involvement/ athletic training, certainly presents themselves as elements expressing tremendous entrepreneurial spirit and discipline (Chang et al., 2017; van de Pol and Kavussanu, 2012). Each of the sport involvement/athletic training factors addressed in this study: fitness, strength and conditioning and endurance training, each served a unique purpose, not only making these participants stand out but also allowing them to develop a positive and more opportunistic outlook in life. This process leads them to become more responsible 
while consistently acting out sound ethical judgement all-round. As a result, the choice to be viewed as a person of positivity and good integrity certainly boosts, rather than limits entrepreneurs to better equip themselves from both a mental and physical perspective consistently (Chang et al., 2017; van de Pol and Kavussanu, 2012). Consequently, this establishes a unique platform for entrepreneurs to confidently face the current challenges and often unethical temptations in entrepreneurship, along with growing their businesses and personal self to the max, encouraging both ethical judgement and advanced policy across all business-related segments in the process.

\section{Conclusion}

\section{Summary}

In this study, the researcher critically explored a combination of sports involvement/athletic training factors, which are believed to be areas of great significance that positively contribute to entrepreneurs' ethical judgement skills. The deriving elements that manifest from the proper execution of the sport involvement/athletic training factors addressed have also proven valuable evidence that the correct implementation of these factors certainly boosts rather than limits entrepreneurs' ethical judgement ability. In addition, the exact lived experiences, as derived from each participant, explained a first-hand approach of how each of the factors was strategically applied, creating a solidified platform for the researcher to accurately interpret the direct effect of each of the factors addressed. Findings from this study suggest a new pathway towards unlocking the true hidden psychological powers that could be derived from active sports involvement/athletic training as a whole. The true benefits derived from sports involvement/athletic training and how it affects ethical judgement ability when applied and channelled correctly can do wonders in terms of solidifying both personal and entrepreneurial performance moving forward. This study, therefore, suggests that the drive to get better, fitter, stronger and more persistent as a human being brings into existence a new appreciation of life and health in general, which develops a more authentic approach to people, situations and circumstances. The results obtained from this study strengthens the fact that the lessons learned from consistently pushing internal boundaries to build and improve ethicality through resilience derived from intense sport-related training, bring to life a whole new perspective that values executing sound ethical judgement all-round.

\section{Limitations}

Prince and Murnan (2004) state that almost all research studies consist of limitations. Although entirely within the recommendations of qualitative IPA research (Smith $e$ t al., 2009), this paper sampled a relatively small number of participants. However, the study's small sample size makes the results very specific and unique to the study's particular industry of choice. This study also addressed a specific group of performance factors that required the researcher to remain in tack with each research question's boundaries, slightly narrowing the scope thereto. In addition, considering the study's phenomenological nature, the researcher's interpretation of the results needs to be regarded as the truth.

\section{Practical implications}

This study addressed the powerful effect that certain factors derived from sports involvement/ athletic training have on entrepreneurs' ethical judgement skills. This study provides a fresh overview of the practical importance of continually engaging in and learning new techniques involving sports/athletic training regimens for entrepreneurs. Results prove that besides contributing physically, the mental benefits and how these factors positively affect 
entrepreneurs' ethical decision-making ability is truly immeasurable. This approach leads the way for existing educational systems to introduce and create new platforms that can train rising entrepreneurs on the ethical benefits that will undoubtedly establish improved public policy, entrepreneurial approach and personal attitudes moving forward. In return, this will set the benchmark for governmental and political sectors to do the same, which will undeniably encourage positive economic and commercial growth. Improved ethical judgement ability derived from sports involvement/athletic training, therefore, is a tremendous asset, an asset that will bolster a culture where mediocrity and dishonesty are not further tolerated.

\section{Theoretical implications}

Theoretically, this study undoubtedly creates a new platform that explicitly contributes to Bandura's self-efficacy theory. The results obtained from this study highlight and introduce a totally different approach to how entrepreneurial cognitive processes can be forged and strengthened through the strategic application of sports involvement and athletic training techniques. In collaboration with Bandura's four existing efficacy-activated processes, results from this study break new ground that deepens the exploration regarding the unique connections among motivation, self-discipline and ethical judgement. Considering that selfdiscipline is widely accepted as good ethic morale (Hagger et al., 2009), the relationship between experiencing physical challenge through sports involvement/athletic training and how it affects the human brain to think, act and judge more ethically, can introduce several new angles of investigation. Therefore, this study presents an ideal platform for researchers to build and explore and possibly add additional concepts to Bandura's four existing efficacy-activated processes.

\section{Recommendations}

This study addressed various aspects that appear to add enormous value within the area of ethical performance research in entrepreneurship. Thus, improved ethical judgement ability remains an area that is strongly encouraged to receive further in-depth attention, as various countries and sectors are still experiencing great difficulty with it. Further studies should be conducted on the powerful effects sports involvement/athletic training has on entrepreneurs' mind-sets and the psychological impact it has on entrepreneurs' ethical decision-making ability. Also, more advanced research should be applied to identify additional ethical judgement factors that might be derived from sports involvement/athletic training. This approach establishes the ultimate opportunity and platform for researchers to continue investigating and potentially conclude new findings and strategies about how these factors can further impact an entrepreneur's attitude, motivation and commitment levels. Finally, it is highly recommended that academic and business researchers and policymakers alike continue to test and apply some of the findings in this study in their own lives as well. It is strongly believed that the benefits derived will undeniably not only contribute to a transformed personal approach to ethical judgement ability and research in general but also impact and strengthen the way ethical judgement ability is viewed and executed in general society, in both South Africa and internationally. This can open a significant doorway that will take ethical judgement research to a whole new level.

\section{References}

Agnew, D., Henderson, P. and Woods, C. (2017), "Ethics, integrity, and Well-Being in elite sport: a systematic review", The Journal of Sport, Vol. 41 No. 2, pp. 1-19. 
Bandura, A. (1993), "Perceived Self-Efficacy in cognitive development and function”, Educational Psychologist, Vol. 28 No. 2, pp. 117-148.

Belle, N. and Cantarelli, P. (2017), "What causes unethical behaviour? A Meta-Analysis to set an agenda for public administration research", Public Administration Review, Vol. 77 No. 3, pp. 327-339.

Bredemeier, B.J. and Shields, D.L. (2006), "Sports and character development", Research Digest President's Council on Physical Fitness and Sport, Vol. 7 No. 1, pp. 1-8.

Calvo, J.C.A. (2011), "Established business owners' success: influencing factors", Journal of Developmental Experience, Vol. 15 No. 3, pp. 263-286.

Chandler, T.J.L. and Goldberg, A.D. (1990), "Building character through sports: Myth or possibility", Counseling and Values, Vol. 34 No. 3, p. 169.

Chang, E.C.H., Chu, C.H., Karageorghis, C.I., Wang, C.C., Tsai, J.H.C., Wang, Y.S. and Chang, Y.K. (2017), "Relationship between mode of sports training and general cognitive performance", Journal of Sport and Health Science, Vol. 6 No. 1, pp. 89-95.

Chimucheka, T. (2020), "Entrepreneurship education in South Africa”, Mediterranean Journal of Social Sciences, Vol. 5 No. 2, pp. 403-416.

Cotterill, J. (2020), "Default at South Africa's land bank increases pressure on Ramaphosa”, available at: https://www.ft.com/content/7d66c09d-15a0-4c32-af07-10ec89ee7c68 (accessed 16 February 2021).

Etikan, I., Musa, S.A. and Alkassim, S. (2015), "Comparison of convenience sampling and purposive sampling", American Journal of Theoretical and Applied Statistics, Vol. 5 No. 1, pp. 1-4.

Fischer, M.V. (2015), "Motivational climate in United States army reserve officer training corps physical training: implications for leadership development, retention, and intervention", Procedia Manufacturing, Vol. 3 No. 1, pp. 1595-1602.

Florin-Valentin, L. and Dariusz, N. (2019), "Integrated training in sports games", Annals of the "Stefan Cel Mare" University: Physical Education and Sport Section - The Science and Art of Movement, Vol. 23 No. 2, pp. 393-433.

Friebel, G., Gallego, J. and Mendola, M. (2013), "Xenophobic attacks, migration intentions, and networks: evidence from the South of Africa", Journal of Population Economics, Vol. 26 No. 2, p. 555 .

Friedman, R. (2014), "Regular exercise is part of your job”, available at: https://hbr.org/2014/10/regularexercise-is-part-of-your-job (accessed 9 November 2020).

Germain, J.L. (2010), "Physical program leadership: from kinesiology in the classroom to fitness training in the field", Quest, Vol. 62 No. 3, p. 287.

Hagger, M.S., Wood, C.W., Stiff, C. and Chatzisarantis, N.L.D. (2009), "Self-regulation and self-control in exercise: the strength-energy model", International Review of Sport and Exercise Psychology, Vol. 3 No. 1, pp. $62-86$.

Hays, G. (2003), Meditations - Marcus Aurelius, Modern Library Books, New York, NY.

Hodges, M.I. and Logan, C.D. (2012), Psychology of Attitudes, Nova Science Publishers, Inc., New York, NY.

Holiday, R. (2015), The Obstacle is the Way, Profile Books Ltd, London.

Holiday, R. (2016), Ego is the Enemy, Profile Books Ltd, London.

Ilies, R., Morgeson, F. and Nahrgang, J. (2005), "Authentic leadership and eudaemonic well-being: understanding leader-follower outcomes”, The Leadership Quarterly, Vol. 16 No. 3, pp. 373-394.

Jarvis, M. (2015), Strength and Conditioning for Football, Bloomsbury Sport, London.

Lederman, N.G. and Lederman, J.S. (2015), "What is a theoretical framework? A practical answer", Journal of Science Teacher Education, Vol. 26 No. 7, pp. 593-597.

Lekovic, B. and Maric, S. (2015), "Measures of small business success/performance - importance, reliability, and visibility", Industrïa, Vol. 43 No. 2, pp. 7-26. 
Lopez, Y.P., Rechner, P.L. and Olson-Buchanan, J.B. (2005), "Shaping ethical perceptions: an empirical assessment of the influence of business education, culture, and demographic factors", Journal of Business Ethics, Vol. 60 No. 4, pp. 341-358.

McCabe, D.L., Butterfield, K.D. and Trevino, L.K. (2006), "Academic dishonesty in graduate business programs: prevalence, causes, and proposed action”, Academy of Management Learning and Education, Vol. 5 No. 3, pp. 294-305.

Morris, B. (2006), “The new rules”, Fortune, Vol. 154 No. 2, pp. 70-87.

Mukerjee, K. (2016), "The psychology of the successful entrepreneur", International Journal of Advanced Engineering and Management, Vol. 1 No. 1, pp. 25-32.

Naderifar, M., Goli, H. and Ghaljaei, F. (2017), "Snowball sampling: a purposeful method of sampling in qualitative research", Strides in Development of Medical Education, Vol. 14 No. 3, pp. 1-6.

Noval, L.J. (2016), "On the misguided pursuit of happiness and ethical decision making: the roles of focalism and the impact bias in unethical and selfish behaviour", Organizational Behavior and Human Decision Processes, Vol. 133 No. 1, pp. 1-16.

Paoli, A. and Bianco, A. (2015), "What is fitness training? Definitions and implications: a systematic review article", Iranian Journal of Public Health, Vol. 44 No. 5, pp. 602-614.

Pietkiewicz, I. and Smith, J.A. (2012), “A practical guide to using interpretative phenomenological analysis in qualitative research psychology", International Journal of Psychology, Vol. 18 No. 2, pp. 361-369.

Prince, J.H. and Murnan, J. (2004), "Research limitations and the necessity of reporting them", American Journal of Health Education, Vol. 35 No. 2, pp. 66-67.

Pritchard, M.P. and Burton, R. (2014), "Ethical failures in sports business: directions for research", Sport Marketing Quarterly, Vol. 23 No. 2, p. 86.

PWC (2020), "Global economic crime and fraud survey 2020", available at: https://www.pwc.co.za/en/ press-room/global-economic-crime-and-fraud-survey-2020.html (accessed 9 November 2020).

Razmus, W. and Laguna, M. (2018), "Dimensions of entrepreneurial success: a multilevel study on stakeholders of micro enterprises", Frontiers in Psychology, Vol. 9 No. 1, pp. 1-11.

Rechner, P. and Smart, D. (2012), "An examination of the effects of sport involvement on ethical judgments in sport and business", Ethics and Behavior, Vol. 22 No. 2, pp. 142-157.

Rees, M.R., Tenbrunsel, A.E. and Bazerman, M.H. (2019), "Bounded ethicality and ethical fading in negotiations: understanding unintended unethical behaviour", Academy of Management Perspectives, Vol. 33 No. 1, pp. 26-42.

Runacres, A., Mackintosh, K.A. and Mcnarry, M.A. (2019), "The effect of constant-intensity endurance training and high-intensity interval training on aerobic and anaerobic parameters in youth", Journal of Sports Sciences, Vol. 37 No. 21, pp. 2492-2498.

Sandelowski, M. (2002), "Re-embodying qualitative inquiry”, Qualitative Health Research, Vol. 12 No. 1, pp. 104-115.

Smith, J.A., Flowers, P. and Larkin, M. (2009), Interpretive Phenomenological Analysis: Theory, Method, and Research, Sage Publications, Inc., London.

Statistics South Africa (2019), "Crime”, available at: www.statssa.gov.za/?cat=26 (accessed 8 October 2019).

Thorne, L. and Saunders, S.B. (2002), "The socio-cultural embeddedness of individuals' ethical reasoning in organisations (cross-cultural ethics)", Journal of Business Ethics, Vol. 35 No. 1, pp. 1-14.

Trompetter, H.R., Lamers, S.M.A., Westerhof, G.J., Fledderus, M. and Bohlmeijer, E.T. (2017), "Both positive mental health and psychopathology should be monitored in psychotherapy: confirmation for dual-factor model in acceptance and commitment therapy", Behaviour Research and Therapy, Vol. 91 No. 1, pp. 58-63. 
Van De Pol, P.K.C. and Kavussanu, M. (2012), "Achievement motivation across training and competition in individual and team sports", Sport, Exercise, and Performance Psychology, Vol. 1 No. 2, pp. 91-105.

Van Rensburg, N. and Kanayo, O. (2020), "Effect of mind-power ability among achieving entrepreneurs in South Africa: identifying accustomed internal drivers", Journal of Entrepreneurship in Emerging Economies, Vol. 12 No. 4, pp. 475-493.

Vitel, S.J., Ramos, E. and Nishihara, C.M. (2010), "The role of ethics and social responsibility in organisational success: a Spanish perspective", Journal of Business Ethics, Vol. 91 No. 4, pp. 467-483.

Vriend, T., Jordan, J. and Janssen, O. (2016), "Reaching the top and avoiding the bottom: how ranking motivates unethical intentions and behaviour", Organizational Behavior and Human Decision Processes, Vol. 137 No. 1, pp. 142-155.

Waegeneer, E.D., Devisch, I. and Willem, A. (2017), "Ethical codes in sports organisations: an empirical study on determinants of effectiveness", Ethics and Behavior, Vol. 27 No. 4, pp. 261-282.

Wang, C.K.J., Tan, L. and Dairianathan, E.I. (2018), "Achievement goals, implicit theories, and intrinsic motivation: a test of domain specificity across music, visual art, and sports", Journal of Research in Music Education, Vol. 66 No. 3, pp. 320-337.

Weiss, M.R. and Gill, D.L. (2005), "What goes around comes around: re-emerging themes in sport and exercise psychology", Research Quarterly for Exercise and Sport, Vol. 76 No. 2, pp. 71-87.

Willig, C. (2001), Introducing Qualitative Research in Psychology: Adventures in Theory and Method, Open University Press, Buckingham.

\section{Corresponding author}

Nico van Rensburg can be contacted at: 3689021@myuwc.ac.za

For instructions on how to order reprints of this article, please visit our website: 